\title{
Global Insights on the Multigenerational Workforce
}
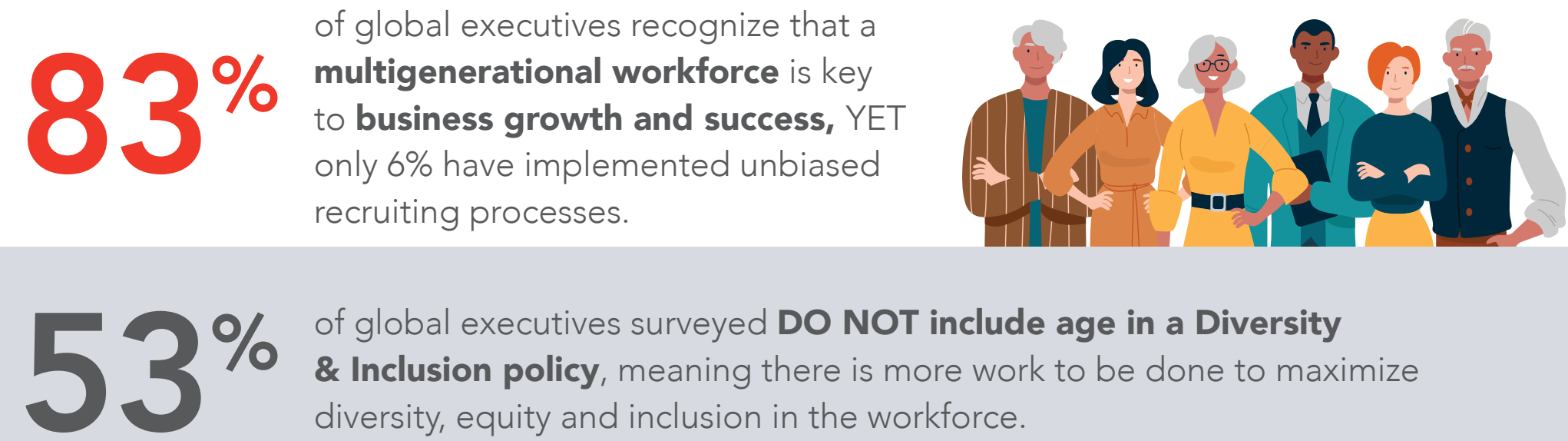

of global executives surveyed DO NOT include age in a Diversity

\& Inclusion policy, meaning there is more work to be done to maximize diversity, equity and inclusion in the workforce.

All workers are aging and there is intersectionality at play across all demographic factors.

\section{$59 \%$ do notincude}

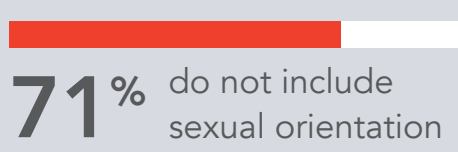

\section{Greater diversity supports higher innovation revenue and profit margins.}

Companies with above-average diversity on their management teams report innovation revenue that is 19 percent higher and profit margins that are 9 percent higher than companies with below-average diversity.

Source: "How Diverse Leadership Teams Boost Innovation." Boston Consulting Group, 2018

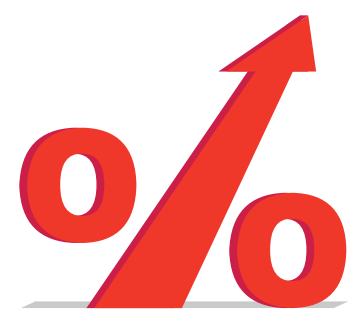

As many are living longer, some will want or need to work longer.

In order to leverage the strengths of the four-to-five generation workforce, global executives are interested in promising practices related to:
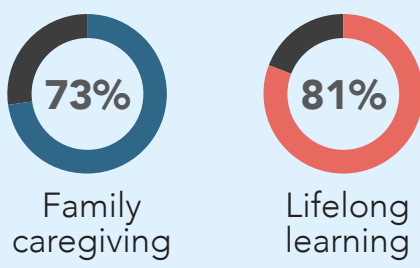

Global executives would implement practices regarding the following if tools and support were available.
70\% Unbiased recruitment

$74 \%$ Training \& lifelong learning opportunities

$68 \%$ Purposefully designed mixed age teams
Yet, barriers persist with $\mathbf{3 8 \%}$ of companies sharing that they have mandatory retirement policies.

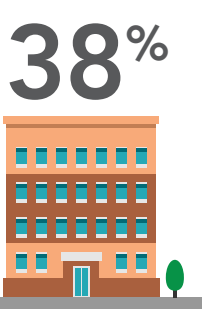

Employers have an important role to play in supporting workers of all ages and life stages in accessing the necessary skill building and other work supports (lifelong learning, caregiving leave, etc.) that allow workers to remain employable over their lifetime.

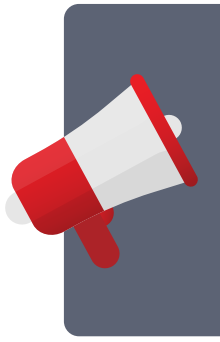

